DOI: https://doi.org/10.47405/mjssh.v5i1.340

\begin{tabular}{|c|c|}
\hline & Malaysian Journal of Social Sciences and Humanities (MJSSH) \\
\hline Malavsian Journal of & Volume 5, Issue 1, January 2020 \\
\hline (MJ - SSH) & e-ISSN : 2504-8562 \\
\hline & $\begin{array}{l}\text { Journal home page: } \\
\text { www.msocialsciences.com }\end{array}$ \\
\hline
\end{tabular}

\title{
Ciri Personaliti Berkualiti Guru Sejarah Tingkatan Enam
}

\author{
Rosy Talin', Sabariah Sharif1, Soon Sigh A/L Bikar Singh', Mohd Shahudin Bin Karim¹ \\ 1Fakulti Psikologi dan Pendidikan, Universiti Malaysia Sabah (UMS) \\ Correspondence: Rosy Talin (rostalin@gmail.com)
}

\begin{abstract}
Abstrak
Penjenamaan semula Tingkatan Enam yang bermula pada tahun 2012 membawa kepada perubahan dalam pentaksiran dan penilaian prestasi pelajar. Ini bermaksud apabila berlaku perubahan dalam pentaksiran dan penilaian prestasi maka berlaku juga perubahan dalam kurikulum. Kumpulan yang menerima impak daripada setiap perubahan yang terjadi adalah guru dan pelajar. Oleh itu, kajian ini, yang menggunakan pendekatan kualitatif, dilakukan untuk meneroka ciri personaliti berkualiti guru tingkatan Enam, khususnya bagi mata pelajaran Sejarah. Pengetahuan ini sedikit sebanyak dapat membantu guru dan pelajar menangani impak perubahan kurikulum yang dihadapi. Model The Big Five Personality telah dijadikan sebagai benchmark untuk menerangkan ciri personaliti berkualiti tersebut. Setelah data yang diperolehi menggunakan kaedah temubual, pemerhatian dan tinjauan dokumen dianalisis, kajian ini mendapati terdapat beberapa keadaan yang menjadi ciri personaliti berkualiti guru sejarah tingkatan Enam di tempat kajian dilakukan.
\end{abstract}

Kata kunci: personaliti berkualiti, sejarah tingkatan enam, prestasi pelajar, pentaksiran dan penilaian

\section{The Quality Personality of Form Six Teachers}

\begin{abstract}
The re-branding of Form Six that started in 2012 has led to the changes in the assessment and evaluation of student performance. This means that when there is a change in the assessment and evaluation of performance there will also be a change in the curriculum. The group that receives the most impact from these changes is the teachers and students. Therefore, this study, which uses a qualitative approach, aims to explore the quality personality of Form Six teachers, especially for History subject teachers. This knowledge can help teachers and students to deal with the impact of the changing curriculum. The Big Five Personality model is used as a benchmark to describe the quality personality traits. After the data is obtained using the interview method, observations and analyzing reviewed documents, this study found that there are several situations in which the quality personality traits in Form Six History teachers of the research location are performed.
\end{abstract}

Keywords: quality personality, history subject teachers, student performance, assessment and evaluation 


\section{Pengenalan}

Pada tahun 2012, Kementerian Pendidikan Malaysia (KPM) telah menyediakan sebuah Pelan Tindakan Pendidikan Malaysia (PTPM). Fungsi PTPM adalah untuk menyediakan program transformasi secara terperinci bertujuan untuk menaik taraf sistem pendidikan negara sesuai dengan pendidikan abad ke21. Salah satu fokus transformasi ini adalah ke atas sistem pembelajaran Tingkatan Enam. Hasilnya berlaku penjenamaan semula Tingkatan Enam yang membawa kepada perubahan dalam pentaksiran dan penilaian prestasi pelajar seperti yang telah diperkenalkan oleh Majlis Peperiksaan Malaysia (MPM). Mengikut Majlis Peperiksaan Malaysia (2012), sistem penaksiran baharu STPM terbahagi kepada dua bentuk iaitu berdasarkan kepada peperiksaan akhir dan penilaian berasaskan sekolah (PBS). Peperiksaan akhir dijalankan sebanyak tiga penggal yang dikendalikan sepenuhnya oleh MPM manakala PBS dimasukkan sebagai nilai wajaran dalam menentukan pencapaian prestasi pelajar dalam peperiksaan. Tujuan perubahan penaksiran dan penilaian ini adalah memartabatkan pendidikan Tingkatan Enam, mengamalkan pentaksiran yang holistik, menyesuaikan pelajar dengan sistem pendidikan prauniversiti, dan membina kemahiran mengurus diri secara berdikari (Majlis Peperiksaan Malaysia, 2012; Kementerian Pendidikan Malaysia, 2013). Perubahan dalam pentaksiran dan penilaian prestasi juga melibatkan perubahan dalam kurikulum dan cara kurikulum itu disampaikan.

\section{Kajian Literatur}

Kumpulan yang mendapat impak secara langsung daripada penjenamaan semula tingkatan enam, selain pelajar, adalah guru kerana merekalah penggerak kurikulum tersebut (Klassen dan Tze; 2014). Sejajar dengan itu, guru-guru tingkatan enam perlu mempunyai ciri-ciri cemerlang, seperti berketerampilan, berilmu, memahami dasar dan aspirasi negara, bersahsiah tinggi, beretika cemerlang, memiliki kemahiran pedagogi bagi meningkatkan kualiti pendidikan (Carpenter, 2008; Cognetta, 2010; Moran, 2010; Thuwayba Ahmad al-Barwani, Wajeha Tahbit al-Ani dan Ismail Hussein Amzat, 2012; Goh dan Wong, 2014). Ciri-ciri ini boleh didapati secara semula jadi atau melalui latihan (Ruys, Van Keer, dan Aelterman, 2011; Hibbs, 2010; Hosman dan Cvetanoska, 2013; Lyle, 2009; Rice, Johnson, Ezell, dan Pierczynski Ward, 2008).

Pemilikan ciri-ciri di atas bergantung kepada personaliti seseorang guru. Beberapa kajian lepas mengaitkan personaliti guru dengan kualiti pengajaran guru (Bremner, 2007; Garcia. P, Ed, Kupczynski, dan Holland, 2011). Seterusnya kajian juga menunjukkan bahawa personaliti guru juga boleh mempengaruhi pencapaian akademik pelajar (Norsaremah Salleh, Mendes, dan Grundy, 2012; Garcia, 2010; Patti Jo White, 2009; Weiss, 2009; Davin, 2007; Westbrook, 2004; dan Muench, 2004). Ini bermakna tiga perkara ini, iaitu, personaliti guru, kualiti pengajaran guru dan pencapaian akademik pelajar mempunyai perkaitan. Oleh itu, Gibson (2010); Yerger dan George (2009) menyatakan pencapaian akademik yang berbeza-beza di setiap sekolah mempunyai kaitan dengan kualiti guru yang mengajar. Jika personaliti guru tersebut tidak digemari oleh pelajar maka pencapaian akademik pelajar turut terkesan (Verst, 2010).

The Big Five Model yang telah dijenamakan semula oleh Saucier dan Goldberg (2003) memberi ciriciri personaliti yang diakronimkan sebagai OCEAN atau NEOAC. Akronim ini mewakili openess to experience keterbukaan kepada pengalaman, conscientiousness /sifat berhati-hati, Extrovent / ekstroversi, Agreeable / menyenangkan, dan Neuroticism/ neurotisism. Ini masih mengekalkan elemen-elemen dalam The Big Five Personality Model yang telah dibentuk oleh Costa dan McCrae (1997). Berikut adalah penerangan ciri-ciri tersebut;

\section{Keterbukaan Kepada Pengalaman}

Ciri keterbukaan kepada pengalaman bermaksud guru memiliki personaliti tenang, mesra, bertanggungjawab dan teliti dalam setiap tindak tanduk di dalam kelas, bersikap ingin tahu berminat untuk mempelajari perkara-perkara baharu (Myers-Briggs Foundation, 2010); prestasi persembahan guru yang tinggi (Laidra, Pullmann, dan Allik, 2007) serta bertimbang rasa dan mengambil perhatian 
terhadap persekitaran kelas. Oleh itu, guru ini terus menerus berusaha untuk mewujudkan persekitaran yang teratur dan harmoni di dalam dan di luar bilik darjah.

\section{Sifat Berhati-hati}

Sifat berhati-hati merujuk kepada guru yang boleh meramal kejayaan akademik. Oleh itu dia memiliki ciri yang sangat teliti dalam menyiapkan matlamat nya dana dalam penyelesaian masalah (Stewart, Fulmer dan Barrick, 2005). Guru ini juga mempunyai rekod prestasi kerja yang baik, iaitu melakukan kerja tepat pada masanya serta kurang senang untuk mengambil cuti kerja (Oswald, Schmitt, Kim, Ramsay, dan Gillespie, 2004). Dia juga jarang merungut kerana mereka mempunyai tabiat kerja yang bertanggungjawab dan gigih, dan tahan uji. Kejayaan akademik pelajar merupakan kepuasan kepada mereka. Oleh itu mereka sangat menjaga kerapian dalam pengajaran, sentiasa teliti dan menepati masa yang ditetapkan dalam rancangan pengajaran agar hasil pembelajaran dapat dicapai. Maka dapat dirumuskan bahawa ciri-ciri personaliti yang teliti, bekerja keras, tepat waktu, sabar, teratur dan bercita-cita tinggi merupakan rangkuman bagi mewakili personaliti berhati-hati.

\section{Extrovent / Ekstroversi}

Guru ini bersikap 'out going,' penuh bertenaga, ekspresif, positif dan pandai bergaul. Semasa berada dalam sesebuah kumpulan, mereka suka sangat bercakap, menilai diri mereka dan mendapat perhatian (Feist dan Feist, 2008). Ciri ini mampu menyumbang kepada kredibiliti guru dalam meningkatkan interaksi pelajar sebab mudah didekati dan mewujudkan persekitaran pembelajaran yang berkesan, selesa dan interaktif (Fisher dan Kent, 2008, Hughes, 2002). Pelajar lebih tertarik dengan guru yang bersifat ekstroversi kerana guru seperti ini gemar menggunakan unsur humor di dalam kelas, mempunyai belas kasihan yang nyata, sikap prihatin terhadap pelajar dan kebimbangan terhadap persekitaran pelajar. Furnham, Petrides, Tsaousis, Pappas, dan Garrod (2005), berpendapat personaliti ekstroversi memberi pengaruh positif. Teven, (2001), (2007a) dan (2007b) dalam kajian mereka mendapati guru yang mengambil berat terhadap muridnya berpengaruh untuk mengubah sikap pelajar yang diajar.

\section{Agreeable / Menyenangkan}

Seseorang yang mempunyai ciri agreeable, berperikemanusiaan, peramah, suka menolong, dermawan dan sanggup berkompromi dengan orang lain, mempunyai pandangan yang optimistik dan sentiasa melihat kebaikan yang ada pada orang lain. Individu seperti ini senang didekati dan sentiasa berusaha mengekalkan hubungan dengan orang lain. Oleh itu mereka dapat mengekalkan kepopularitian dalam kumpulan (Feist dan Feist, 2008). Seseorang guru yang mempunyai ciri ini mempunyai kemahiran interpersonal yang sangat baik, kurang sifat kebergantungannya, sentiasa mengekalkan prestasinya dan mengurangkan masalah dalam kerjaya. Juga guru ini bersemangat dan mesra di samping mempunyai daya imaginasi yang amat baik. Mereka melihat kehidupan dengan penuh dengan kemungkinan. Oleh itu mereka bersiap sedia dengan apa jua perkara yang berlaku di dalam kelas supaya kelas berlangsung dengan sempurna. Guru ini juga mudah membuat persetujuan dan berasa yakin di samping mudah memberi penghargaan dan sokongan. Guru ini juga memiliki sifat yang fleksibel (Myers-Briggs Foundation, 2010). Ciri personaliti ini adalah lembut hati, percaya pada diri, murah hati, lemah lembut, baik hati, namun cepat berbelah bagi.

\section{Neuroticism / Neurotisism}

Mereka yang memiliki ciri personaliti ini sentiasa bersifat negatif seperti mempunyai sifat marah, kemuraman (depression), ketakutan atau kebimbangan pada sesuatu isu. Ini kerana mereka mempunyai emosi yang berlebih-lebihan terhadap sesuatu perkara yang biasa saja. Jadi mereka sentiasa bersikap reaktif. Pemilik ciri personaliti ini sentiasa berasa tertekan dan tidak dapat berfikir secara logik dan waras (Myers-Briggs Foundation, 2010). Guru perlu mempunyai ciri ini pada tahap yang rendah supaya dia dapat mengamalkan kelas interaktif (Chamorro-Premuzic dan Furnham, 2013) dan menggunakan teknik-teknik yang lebih berkesan dalam pengajaran dan pembelajaran. Walau bagaimanapun, terdapat kajian menyatakan guru yang memiliki sifat neurotism yang rendah ini 
biasanya apabila bekerja dalam kumpulan mereka jarang memberi bantuan kepada orang lain (Porter, Hollenbeck, Ilgen, Ellis, West, dan Moon, 2003) walaupun mereka menyumbang kepada ketenangan dan kurang mengganggu dalam kumpulan (Reilly, Lynn, dan Aronson, 2002). Ketenangan mereka ini menyebabkan pelajar kurang bermotivasi kerana guru sedemikian kurang memikirkan masalah pelajar sehingga kurang membantu dalam mendidik pelajarnya (Myers-Briggs Foundation, 2010). Kesimpulannya, ciri-ciri personaliti ini adalah tenang, pandai mengawal emosi, berpuas hati terhadap diri sendiri, selesa, tidak beremosi serta tahan lasak (Fincham dan Rhodes, 2005).

Beberapa kajian lalu sudah melihat ciri-ciri personaliti guru. Misalnya kajian Todorovi, Stojiljkovi, dan Djigi, (2012); Kneipp, Kelly, Briscoe, dan Richard, (2010); Selvam, (2000) ciri personaliti guru daripada perspektif guru. Manakala kajian oleh Chi, Yeh, dan Choum, (2013) pula menumpukan kepada pandangan pelajar tentang ciri personaliti guru dalam pengajaran.

Oleh itu, kajian ini ingin meneroka ciri personaliti yang perlu ada dalam personaliti berkualiti guru, khususnya guru Sejarah. Guru Sejarah dipilih kerana Sejarah merupakan subjek penting untuk membantu kemasukan pelajar ke universiti di samping Pengajian Am. Untuk mencapai objektif ini dua persoalan perlu dijawab; apakah ciri personaliti guru yang diberi keutamaan oleh pelajar dalam pengajaran dan pembelajaran bagi meningkatkan pencapaian akademik mereka, dan, bagaimanakah ciri personaliti yang menjadi keutamaan guru dalam meningkatkan kualiti pengajaran dan pembelajaran Sejarah. Kedua-dua pandangan daripada kedua-dua pihak, pelajar dan guru, dibandingbezakan untuk mendapatkan ciri personaliti berkualiti guru Sejarah.

\section{Metod Kajian}

Kajian ini menggunakan kaedah kualitatif kerana tujuan utama kajian adalah menyelidiki secara mendalam ciri yang diperlukan dalam personaliti berkualiti guru Sejarah. Untuk mendapatkan data yang sesuai, sampel bertujuan digunakan. Kajian ini dilakukan di dua buah sekolah menengah yang mempunyai keputusan mata pelajaran Sejarah yang terbaik di Sabah. Secara tidak langsung kajian ini dilakukan secara kajian kes. Dua orang guru Sejarah yang terlibat mengajar Sejarah tingkatan enam di kedua-dua sekolah ini dan seramai empat orang pelajar yang mendapat keputusan yang baik menjadi responden kajian.

Pengumpulan data dilakukan secara temubual, pemerhatian dan dokumen analisis. Untuk temubual, ia dilakukan separa berstruktur. Ini bermaksud soalan yang diajukan digubal terlebih dahulu namun urutan soalan, cara soalan diajukan, dan bentuk soalan boleh berubah-ubah, bergantung kepada reaksi dan tindak balas yang diberi oleh responden dan mengikut persepsi penemu bual berdasarkan apa yang dirasakan perlu atau bersesuaian pada waktu ketika temu bual dijalankan. Pengurangan soalan yang dirasakan tidak sesuai atau penambahan soalan mengikut keperluan semasa sesi temubual turut dilakukan (Robson, 2002). Sebanyak 18 temubual dilakukan ke atas responden.

Bagi aktiviti pemerhatian, pemerhatian terhadap proses pengajaran dan pembelajaran di dalam kelas dilakukan berdasarkan protokol pemerhatian yang telah disediakan. Pemerhatian di dalam bilik darjah dilakukan semasa guru sedang mengajar subjek Sejarah. Responden diperhatikan tanpa penglibatan daripada pengkaji. Ini mengambil nasihat Miles dan Huberman (2014) yang menyatakan pemerhati penuh tidak terlibat secara langsung dengan aktiviti yang dijalankan oleh responden. Sebamyak empat pemerhatian dilakukan ke atas responden guru.

Analisis dokumen dilakukan dengan melihat dokumen yang berkaitan dengan proses pengajaran dan pembelajaran seperti Rancangan Pengajaran Harian, nota-nota pelajar, gambar-gambar dan rakaman video yang berkaitan dengan responden. Analisis dokumen berfungsi untuk mentriangulasikan data. Di samping itu, analisis biodata guru juga turut diambil kira untuk melihat pencapaian guru dalam kerjaya mereka sebagai seorang guru Sejarah yang berpengalaman.

Untuk menganalisis data, tiga jenis pengekodan digunakan, iaitu (a) pengekodan terbuka, untuk mengenalpasti kata kunci, (b) pengekodan paksi untuk mewujudkan kategori atau sub kategori 
DOI: https://doi.org/10.47405/mjssh.v5i1.340

daripada pengekodan terbuka, dan (c) pengekodan terpilih, iaitu membuat hubungan antara kategori dan subkategori bagi mewujudkan tema serta pattern dan seterusnya idea-idea yang belum kelihatan sebelum ini. Idea-idea ini dikenali sebagai emergent theme. Pengekodan dijalankan secara manual. Untuk pengekodan terbuka dan pengekodan paksi, pendekatan within case analyses digunakan, manakala untuk pengekodan terpilih, pendekatan cross-case analisis (Glaser dan Strauss, 1999) digunakan. Analisis ini digunakan bertujuan untuk menginterpretasi keseluruhan data yang diperoleh.

\section{Dapatan Kajian}

Selepas data guru dan data pelajar dianalisis, terdapat tiga ciri personaliti yang sepadan. Ciri-ciri yang sepadan ini diterima sebagai ciri personaliti berkualiti yang ada pada guru Sejarah.

\section{Ekstroversi}

Guru sentiasa proaktif di dalam kelas, ikut serta dalam aktiviti pengajaran baik di dalam mahupun di luar bilik darjah, memberi galakan kepada pelajar-pelajar untuk terus belajar, sentiasa mempunyai idea menarik dan memiliki daya penarik, dan mempunyai unsur kecindan dalam pengajaran. Walaupun guru sering menggunakan unsur kecindan di dalam kelas, namun guru ini masih memiliki sifat keprihatinan yang sangat tinggi terhadap pelajar. Meksophawannagul (2015), menyatakan guru yang menerapkan unsur kecindan dalam pengajaran biasanya mewujudkan pengajaran berkesan di dalam kelas. Manakala kajian Stroud (2016) menyatakan guru yang mempunyai sifat ekstroversi, menyebabkan pelajar berasa selesa dengan persekitaran pembelajaran yang dilaluinya dan ini meningkatkan minat pelajar untuk belajar.

\section{Keterbukaan kepada pengalaman}

Ciri ini termasuklah keaslian sifat guru semasa menyampaikan pengajaran (original), inovatif, penuh dengan ciri keunikan, kreatif dan kritis, berpendirian teguh, imaginatif dan menyukai kepelbagaian dalam gaya pengajaran. Sifat berhati-hati guru amat kelihatan apabila guru menganalisis setiap pelajar menyebabkan pelajar merasai guru sangat mengenali latar belakang mereka, dan mereka berasa selesa dengan pengajaran guru tersebut. Kajian Burke (2015) menyatakan guru yang memiliki ciri keterbukaan kepada pengalaman ini dilihat sebagai seorang ikon yang diteladani dalam pembelajaran.

\section{Berhati-hati}

Berhati-hati yang kelihatan dalam data adalah sikap guru yang ambiltahu tentang latarbelakang ekonomi pelajar, permasalahan peribadi pelajar dan tingkah laku pelajar tersebut. Guru tidak bertanya secara terus kepada para pelajarnya, namun mengambil inisiatif untuk mencungkil kehidupan pelajar tersebut di dalam dan di luar sekolah. Sikap ini telah membawa beberapa perubahan positif dalam kalangan pelajar. Hasil kajian ini menyokong dapatan kajian yang pernah dijalankan oleh Leijen et al., (2017) iaitu apabila guru sentiasa berhati-hati dalam membuat keputusan pengajaran maka teknik pengajaran guru tersebut juga semakin mantap dan digemari pelajar.

\section{Perbincangan}

Ketiga-tiga ciri ini selari dengan saranan dalam teori tindakan Brookhart, Moss, dan Long, (2009), (2010). Pengajaran berdasarkan teori tindakan dikategorikan sebagai pengajaran paling berkesan kerana ia menyediakan pembelajaran bermakna kepada pelajar. Ia berlaku apabila guru membentuk sasaran yang tepat terhadap pembelajaran pelajar. Caranya guru bersama-sama dengan pelajar membentuk matlamat bagi menilai pemahaman mereka terhadap sesuatu pengetahuan. Teori tindakan yang digunakan oleh guru secara berterusan dalam proses penilaian formatif dapat meningkatkan pencapaian pelajar. Perkara yang perlu diutamakan dalam pengajaran berkesan ialah sasaran guru tersebut terhadap pembelajaran pelajar. 
Sasaran pembelajaran berlaku apabila seseorang guru bertindak sebagai seorang yang mesra pelajar dengan memberi penerangan yang pelbagai secara lisan, tayangan gambar, tindakan 'hands-on', ataupun gabungan ketiga-tiga cara tersebut. Pelaksanaan amalan dalam teori tindakan ini selari dengan apa yang dicadangkan oleh pelajar sebagai sesuai untuk dilaksanakan dalam pengajaran. Apabila sasaran pembelajaran dikongsi bersama, ia secara tidak langsung dapat menjadikan pembelajaran tersebut semakin bermakna. Apabila guru dan pelajar mempunyai sasaran yang sama, sesi pengajaran dan pembelajaran dapat dilakukan dengan mudah sebab kedua-dua pihak mengetahui perkara yang ingin dijangka dan diharapkan. Peranan guru adalah merancang, memantau, menilai dan meningkatkan kualiti pembelajaran pelajar untuk meningkatkan pencapaian akademik semua pelajar.

Apabila pendidik berkongsi sasaran pembelajaran dengan pelajar sepanjang pengajaran, mereka sentiasa merangka dan menilai semula apa yang dianggap sebagai bukti pengajaran dan pembelajaran yang bermakna. Guru melibatkan diri dalam pembelajaran pelajar secara berulang kali dengan mempersoalkan diri sendiri terhadap kepercayaan dan amalan pengajaran semasanya (Brookhart, Moss, dan Long, 2009, 2010).

\section{Kesimpulan}

Ketiga-tiga ciri personaliti yang ditemukan dalam kajian ini, iaitu, ektroversi, keterbukaan kepada pengalaman dan sifat berhati-hati merupakan keutamaan yang diberikan oleh pihak guru dan pihak pelajar. Jelas, ketiga-tiga ini membentuk ciri personaliti guru yang dianggap berkualiti dalam pengajaran dan pembelajaran Sejarah dan ia terkandung dalam teori tindakan yang menjelaskan pengajaran yang berkesan dan bermakna. Tidak hairanlah pelajar-pelajar yang menjadi responden dalam kajian ini mendapat keputusan yang baik dalam mata pelajaran Sejarah. Walau bagaimanapun, dapatan kajian ini hanyalah untuk menerangkan ciri-ciri personaliti berkualiti bagi guru-guru di lokasi kajian sahaja. Kajian seumpama ini perlu diteruskan ke lokasi kajian yang lain untuk mendapatkan gambaran seterusnya ciri-ciri personaliti berkualiti guru sejarah tingkatan enam.

\section{Rujukan}

Bremner, T. J. (2007). Exploring the Relationship Between Myers-Briggs Personality Type and Academic Success for Students of English as a Foreign Language Enrolled at a Russian University. German: VDM Verlag.

Brookhart, S. M., Moss, C. M., \& Long, B. A. (2009). Promoting Student Ownership of Learning Through High-Impact Formative Assessment Practices. Journal of Multi Disciplinary Evaluation, 6(12), 52-67.

Brookhart, S. M., Moss, C. M., \& Long, B. A. (2010). Teacher Inquiry Into Formative Assessment Practices In Remedial Reading Classrooms. Assessment in Education: Principles, Policy \& Practice, 17(1), 41-58.

Burke, K. J. (2015). Curricular Documents and the Positioning of Teachers and Students in Catholic Schools: The Cult of Personality. Religion and Education, 42(3), 321-338.

Carpenter, S. (2008). A Grounded Theory Study of the Professional Preparation Process of Alabama Urban High School Alternative Certified Teachers. Tesis Ph.D. Birmingham: The University of Alabama.

Chi, H., Yeh, H., \& Choum, S. (2013). The Organizational Commitment, Personality Traits and Teaching Efficacy of Junior High School Teachers: The Meditating Effect of Job Involvement. The Journal of Human Resource and Adult Learning, 9(2), 131-143.

Cognetta, S. (2010). Preparing Students For a Twenty First Century Global Workplace in an Era of Accountability. Tesis Ph.D. California: Faculty of the Usc Rossier School of Education, University Of Southern California.

Davin, A. S. (2007). Character Education in Poverty Area Elemantary Schools: The Perspectives of Parents and Teachers. Oakland: University Rochester, Michigan.

Feist, Jess \& Feist, Gregory, J. (2008). Theories of Personality. (7th Edition). United States: McgrawHill. 
Fenderson, P. R. (2011). Personality Characteristics of 2009 National Teacher of the Year Candidates. Tesis Ph.D. Washington: Walden University.

Fincham, R., \& Rhodes, P. (2005). Principals of Organizational Behavior. (4th ed.). New York, NY: Oxford University Press.

Fisher, D. L., \& Kent, H. B. (2008). Association Between Teacher Personality and Classroom Environment. Journal of Classroom Interaction. 33(1), 5-13.

Furnham, A., Nuygards, S., \& Chamorro-Premuzic, T. (2013). Personality, Assessment Methods and Academic Performance. Instructional Science. 41(5), 975-987.

Furnham, A., Petrides, K. V., Tsaousis, I., Pappas, K., \& Garrod, D. (2005). A Cross- Cultural Investigation Into The Relationships Between Personality Traits and Work Values. Journal of Psychology. 139(1), 5-32.

Garcia, P., Ed, D., Kupczynski, L., \& Holland, G. (2011). Impact of Teacher Personality Styles on Academic Excellence of Secondary Students. National Forum of Teacher Education Journal. 21(3), 1-8.

Garcia, P. L. S. (2010). The Impact of Teacher Personality Styles on the Academic Excellence of Secondary Students. Texas: University Kingsville.

Gibson, S. K. (2010). What Parents Expect of Urban Alternative Schools and How These Schools Address Parents' Expectations to Make Needed Changes. University of Cincinnati.

Glaser, B. G., \& Strauss, A. L. (1999). The Discovery of Grounded Theory: Strategies for Qualitative Research. New Brunswick: Aldine Transaction Publishers.

Goh, P. S. C., \& Wong, K. T. (2014). Beginning Teachers' Conceptions Of Competency: Implications To Educational Policy And Teacher Education In Malaysia Author. Educational Research for Policy and Practice. 13(1), 65-79.

Hibbs, T. S. (2010). Teachers Perspectives About Implementing a Content-Specific Technology Innovation. Colorado: University of Denver.

Hosman, L., \& Cvetanoska, M. (2013). Technology, Teachers and Training: Combining Theory With Macedonia's Experience. International Journal of Education. 9(3), 28-49.

Hughes, J. N. (2002). Authoritative Teaching: Tipping the Balance In Favor of School Versus Peer Effects. Journal of School Psychology. 40, 485-492.

Klassen, R. M., \& Tze, V. M. C. (2014). Teachers' Self-Efficacy, Personality and Teaching Effectiveness: A Meta-Analysis. Educational Research Review. 12, 59-76.

Kneipp, L. B., Kelly, K. E., Briscoe, J. D. \& Richard, B. (2010). The Impact of Instructor's Personality Characteristics on Quality of Instruction. College Student Journal. 44(4), 91-95.

Kementerian Pendidikan Malaysia (2013). Pelan Pembangunan Pendidikan Malaysia. Putrajaya: Kementerian Pendidikan Malaysia.

Laidra, K., Pullmann, H., \& Allik, J. (2007). Personality and Intelligence as Predictors of Academic Achievement: A Cross-Sectional Study From Elementary To Secondary School. Personality and Individual Differences. 42: 441-451.

Leijen, A., Slof, B., Malva, L., Hunt, P., Tartwijk, J. Van \& Schaaf, M. Van Der. (2017). Performance-Based Competency Requirements for Student Teachers and How to Assess Them. International Journal of Information and Education Technology. 7(3), 190-194.

Lyle, B. K. E. (2009). Teachers' Perceptions of Their Technology Education Curricula. Pennsylvania: Immaculata Univeristy.

Meksophawannagul, M. (2015). Teacher and Learner Views on Effective English Teaching in the Thai Context: The Case of Engineering Students. English Language Teaching. 8(11), 99-117.

Miles, M. B., \& Huberman, A. M. (2014). Qualitative Data Analysis: A Methods Sourcebook. (3rd ed.). Thousand Oaks, CA: SAGE Publications.

Moran, J. (2010). Synthesis of Frequently-Cited Criteria That Contribute To Outstanding K-12 Teaching in the 21st Century. Virginia: University of Nevada, Reno.

Majlis Peperiksaan Malaysia. (2012). Laporan Tahunan 2011. Kuala Lumpur: Penerbitan Pelangi Sdn. Bhd.

Muench, S. J. (2004). Giver, Organizer, Adventurer, or Thinker? An investigation Into The Usefulness of "The Personality Spectrum" for Higher Education. Tesis Ph.D. Carlifornia: Fielding Graduate University. 
Norsaremah Salleh, Mendes, E., \& Grundy, J. (2012). Investigating the Effects of Personality Traits on Pair Programming in a Higher Education Setting Through a Family of Experiments. Empirical Software Engineering. 19(3), 714-752.

Oswald, F. L., Schmitt, N., \& Kim, B. H. (2004). Developing a Biodata Measure and Situational Judgment Inventory as Predictors of College Student Performance. Journal of Applied Psychology. 89(2), 187-207.

Patti Jo White. (2009). The Decision to Stay: A Multiple-Case Study Exploring College Choice and Persistence Factors of Second-Year Students at Religiously- Affiliated Institutions Associated With the Churches of Christ.vTesis Ph.D. Litle Rock: University of Arkansas at Little Rock.

Porter, C. O. L. H., Hollenbeck, J. R., Ilgen, D. R., Ellis, A. P. J., West, B. J., \& Moon, H. (2003). Backing Up Behaviors in Teams: the Role of Personality and the Legitimacy of Need. Journal of Applied Psychology. 88: 391-4.

Reilly, R. R., Lynn, G. S., \& Aronson, Z. H. (2002). The Role of Personality in New Product Development Team Performance. Journal of Engineering and Technology Management. 19(1), 39-58.

Rice, M. P., Johnson, D., Ezell, B., \& Pierczynski-Ward, M. (2008). Preservice Teachers' Guide For Learner-Centered Technology Integration Into Instruction. Interactive Technology and Smart Education. 5(2), 103-112.

Ruys, I., Van Keer, H., \& Aelterman, A. (2011). Student Teachers' Skills in the Implementation of Collaborative Learning: A Multilevel Approach. Teaching and Teacher Education. 27(7), 10901100 .

Robson, C. 2002. Real World Research: A Resource for Social Scientists and Practioner-Researchers. (2th Edition). Oxford: Blackwell Publisher.

Saucier, G., \& Goldberg, L. (2003). The Structure of Personality Attributes dalam M. R. Barrick \& A. M. Ryan (Eds.). Personality and Work: Reconsidering the Role of Personality in Organizations. San Francisco, CA: Jossey-Bass.

Selvam, D. (2000). Pengaruh Personaliti Terhadap Prestasi Kerja di Kalangan Guru-guru Sekolah Menengah. Sintok: Universiti Utara Malaysia.

Stewart, G. L., Fulmer, I. S., \& Barrick, M. R. (2005). An Exploration of Member Roles as a Multilevel Linking Mechanism For Individual Traits and Team Outcomes Personnel Psychology. 58(2), 343-365.

Stroud, S. R. (2016). Democracy, Partisanship, and the Meliorative Value of Sympathy In John Dewey's Philosophy of Communication. Journal of Speculative Philosophy. 30(1), 75-93.

Teven, J. J. (2001). The Relationship Among Teacher Characteristics and Perceived Caring. Communication Education. 50(2), 159-169.

Teven, J. J. (2007a). Teacher Caring and Classroom Behavior: Relationships With Student Affect and Perceptions of Teacher Competence and Trustworthiness. Communication Quarterly. 55(4), 433450.

Teven, J. J. (2007b). Teacher Temperament: Correlates With Teacher Caring, Burnout and Organizational Outcomes. Communication Education. 56(3), 382- 400.

Thuwayba Ahmad Al Barwani, Wajeha Tahbit Al-Ani, \& Ismail Hussein Amzat. (2012). An Effective Teaching Model For Public School Teachers in the Sultanate of Oman. Education, Business and Society: Contemporary Middle Eastern Issues. 5(1), 23-46.

Todorovi, J., Stojiljkovi, S., \& Djigi, G. (2012). Basic Personality Dimensions and The Attitudes of Primary and Secondary School Teachers Towards Inclusive Education. Journal of Educational Sciences \& Psychology. II(1), 66-76.

Verst, A. L. (2010). Outstanding Teachers and Learner-Centered Teaching Practices at a Practices at a Private Liberal Arts Institution. Tesis Ph.D. Tucson: The University of Arizona.

Weiss, D. A. (2009). Personality Development and its Role in School Performance Among American Indian Youth. Louisiana: Tulane University.

Westbrook, G. W. (2004). An Investigation of the Effects of Teacher Personality on Teacher Behaviors in the Instrumental Music Classroom: A Path Analysis. International Journal of Arts and Commerce. 2(2), 129-144.

Yerger, C., \& George, S. (2009). An Action Research Study: How Can Elementary Teachers Collaborate More Effectively with Parents to Support Student Literacy Learning. New York: University of Rochester. 